\title{
Oil and pump prices: Testing their asymmetric relationship in a robust way
}

\author{
Zacharias Bragoudakis $^{1}$, Stavros Degiannakis ${ }^{1,2}$, George Filis ${ }^{3 *}$
}

${ }^{1}$ Bank of Greece, Economic Research Department, 21 E. Venizelos Avenue, GR10250, Athens, Greece.

${ }^{2}$ Department of Economics and Regional Development, Panteion University of Social and Political Sciences, 136 Syggrou Avenue, 17671, Greece.

${ }^{3}$ Department of Accounting, Finance and Economics, Bournemouth University, 89

Holdenhurst Road, Executive Business Centre, BH8 8EB, Bournemouth, UK.

*Corresponding author's email: gfilis@bournemouth.ac.uk

\begin{abstract}
:
The aim of this study is to provide a novel method to assess whether retail fuel prices respond asymmetrically to changes in the international crude oil prices. To do so, we consider the whole supply chain, we use daily data and we depart from the current practice in the literature that focuses on prices. Rather, we consider the markups of both the refineries and retailers. Hence, we show that we first need to assess whether the refineries' mark-up responds asymmetrically to the international crude oil prices and subsequently whether the retailers' mark-up shows an asymmetric behaviour relatively to changes in the refined fuel prices. Focusing in Greece as our case study, our findings show that Greek fuel retailers do not change their mark-up behaviour based on changes of the refined fuel price. By contrast, the asymmetric behaviour is evident in the refineries' mark-up relatively to changes in the international crude oil prices, which is then passed through to the retailers and consumers. Finally, we provide evidence that weekly and monthly data mask any such asymmetric relationship. Thus, we maintain that unless the appropriate data frequency, fuel price transformations and the whole supply chain are considered, misleading findings could be revealed.
\end{abstract}

Keywords: Oil price shocks, fuel prices, asymmetric responses, rockets and feathers, pass-through.

JEL codes: C22, C32, D40, Q41. 


\section{Introduction}

International crude oil prices have experienced huge swings since 2007, when they fluctuated from about $\$ 60$ per barrel to a record high of $\$ 145$ in 2008 and subsequently dropped sharply at about $\$ 30$ in late 2008 , or even during the period 2014-2015, when oil lost about 75\% of its price. Recently, during 2016 to 2019, oil prices experienced another period of abrupt change rising from about $\$ 30$ (January 2016 ) to $\$ 78$ (September 2018), then dropping back to the levels of $\$ 50$ in December 2018 before they bounce back to almost \$70 in April 2019.

Furthermore, over the last decade or so we have observed the increased financialisation of the oil market, which, in many cases, has resulted in abrupt changes in oil prices (Buyuksahin and Robe, 2014; Le Pen and Sévi, 2017). Such developments certainly affect the pricing strategies of oil companies in both the upstream and downstream sector. Although it primarily affects the former sector given their large fixed costs, similar observations have been extensively reported for the downstream sector, as well.

Indeed, there is a wealth of literature that assesses the effects of crude oil price fluctuations on the pump price and whether the response of the latter is asymmetric towards increases and decreases of the former (some recent studies include Valadkhani et al., 2015; Rahman, 2016; Apergis and Vouzavalis, 2018; Eleftheriou et al. 2018; Kang et al., 2018). This asymmetric behaviour has been characterised by a term coined by Bacon (1991) called rockets and feathers. The rockets and feathers phenomenon suggests that when crude oil prices increase then there is an immediate increase in pump fuel prices; whereas during crude oil prices decreases, pump prices tend to adjust at a much slower pace. Perdiguero-García (2013), Kristoufek and Lunackova (2015) and more recently Cook and Fosten (2018) provide an extensive review of this line of research. On the whole, the existing evidence demonstrates several interesting regularities.

First, the reported findings do not reach a consensus since there are studies that find evidence in favour of the asymmetric behaviour (see for instance, DuffyDeno, 1996; Balke et al., 1998; Grasso and Manera, 2007; Blair et al., 2017), whereas other studies cannot provide any support to such claims (Shin, 1994; Godby et al., 2000; Balaguer and Ripollés, 2012; Karagiannis et al., 2015).

Second, studies concentrate their attention to the effects of oil prices on the pump prices, largely ignoring the effects of the former on the refining industry (see 
for instance, Manning, 1991; Borenstein et al., 1997; Godby et al., 2000; Meyler, 2009; Rahman, 2016; Apergis and Vouzavalis, 2018). Delpachitra (2002) is one of scarce studies that shows that price adjustments in the domestic market do not respond effectively to changes in the international oil prices. By contrast, they report that domestic wholesale prices are the key to determining retail prices. Thus, the lack of competition in the wholesale market was found to be the main cause of the weak adjustment of retail prices. Galeotti, et al. (2003) and Kaufmann and Laskowski (2005) also focus on the refining industry, although they reach to different conclusions. The former study focuses on five European countries (Germany, Spain, France, Italy and the UK) and show that asymmetric behaviour is evident in both the refining and distribution stages. By contrast, Kaufmann and Laskowski (2005) study the US market and they show that the refining margin does not exhibit any asymmetric behaviour towards changes in the crude oil prices. More recently, Balaguer and Ripollés (2012) find evidence in favour of a symmetric behaviour of retail fuel prices to changes in the wholesale prices.

Third, the most common data frequency that is considered by the existing literature is either weekly or monthly (e.g. Kirchgässner and Kübler, 1992; Shin, 1994; Duffy-Deno, 1996; Godby et al., 2000; Bermingham and O'Brien, 2011). Authors have almost ignored the potential effects at daily frequency with some exception to include the studies by Bachmeier and Griffin (2003), Oladunjoye (2008) and recently Gautier and Saout (2015) and Lahiani et al. (2017).

Forth, studies in this line of research most commonly employ techniques such as the asymmetric error correction model (or variants of this model), threshold autoregressive and momentum threshold autoregressive (TAR and MTAR) models and panel regressions (see, Manning, 1991; Balke et al., 1998; Bettendorf et al., 2003; Grasso and Manera, 2007; Panagiotidis and Rutledge, 2007; Douglas, 2010; Balaguer and Ripollés, 2016, among others). Table 1 provides a summary of some selected studies.

\section{[TABLE 1 HERE]}

It is rather evident from the brief overview of the related literature that there are certain gaps in this line of research, which are considered in this study.

First, we are among the very few studies that concentrate on the whole supply chain from the international crude oil prices to the pump prices so to identify where there might be any asymmetric behaviour. 
Second, we consider three different data frequencies (daily, weekly and monthly) in order to assess whether lower frequencies mask any asymmetric behaviour.

More importantly, though, we depart from the current practice in the literature that centres its attention solely on pump prices. Rather, our focus is on both the refineries and retailers, as well as, on their mark-ups rather than on refined fuel and pump prices. We do so since refined fuel and pump prices may not necessarily reveal the pricing strategy of both refineries and retailers. However, the asymmetric behaviour is expected to be impacted by the mark-up that refineries and/or retailers will charge on top of the import cost of oil and purchase price of refined fuel, respectively. For instance, there could be cases where pump prices may not change due to declines in crude oil prices; however, this could be due to changes in taxation, while the mark-up remains constant. Hence, in such case, the identification of the asymmetric behaviour would be inappropriately identified. Thus, it is important to assess first whether the refineries' mark-up responds asymmetrically to the international crude oil prices and subsequently whether the retailers' mark-up shows an asymmetric behaviour relatively to changes in the refineries' fuel prices.

Brown and Yücel (2000) have claimed that the observed asymmetry in the pump prices could be sourced to the changing profit margins (i.e. mark-ups) of retailers, although they did not formally test this claim in the same fashion as we do in the present study.

Against this backdrop, the aim of this paper is to investigate the impact of the international crude oil prices on the oil downstream sector, focusing on both the refining industry, as well as, the retail (petrol stations) sector, using a novel approach. Our case study is the Greek fuel market given the industries characteristics, as well as, due to the fact that we can employ a unique dataset, which is available on a daily basis and it is not publicly available (details can be found in Section 2).

We should highlight that there are scarce studies that focus on the Greek downstream oil sectors. One such study is by Angelopoulou and Gibson (2010) who focus on the different prefectures of the Greek region and do not support the view that pump prices asymmetrically respond to positive and negative changes in the crude oil prices. They further suggest that any observed asymmetry is due to the tax changes. Similar results are also provided by a recent study of Apergis and Vouzavalis (2018), who report a symmetric pass-through of crude oil prices to retail pump prices. 
By contrast, Polemis (2012) maintains that the reactions of the retail fuel prices to wholesale price decreases and increases are asymmetric. The findings by Bragoudakis and Sideris (2012), regarding the retail sector, corroborate those of Polemis (2012).

Succinctly put, our findings show that our novel approach allows us to uncover the true relationships (asymmetric or symmetric). In particular, using the whole supply chain and the downstream sector's daily mark-ups, rather than prices, we show that the Greek fuel retailers do not alter their mark-up behaviour based on positive or negative changes of the refined fuel prices (symmetric behaviour). By contrast, the asymmetric behaviour is evident in the refineries' mark-up relatively to positive and negative changes in the crude oil prices, which is then passed through to the retailers and consumers. Worth noting is the evidence that weekly and monthly data do mask the asymmetric relationship along the whole supply chain. Thus, we demonstrate that unless appropriate transformation of the data and the whole supply chain are considered, results may reveal misleading conclusions.

The structure of the remaining paper is as follows. Section 2 presents the data and methods used in this study. Section 3 provides evidence in favour of an asymmetric relationship between crude oil prices and pump prices, while Section 4 remodels the relationship between crude oil and pump prices. Section 5 provides i) a series of robustness tests using weekly and monthly data and ii) develops a framework that accounts for a nonzero threshold parameter in order to distinguish between asymmetric changes in crude oil (and refinery prices). Finally, Section 6 concludes the study.

\section{Data and methods}

\subsection{Data description}

As shown in Section 1 and Table 1, previous studies mainly consider weekly or monthly data, employ mainly asymmetric error correction models and focus on crude oil and pump prices. We depart from these standard approaches, considering daily data, employing a short-run model and focusing on the mark-ups of refineries and retailers, rather than on crude oil and fuel prices. We maintain that in order to assess any asymmetric behaviour in fuel prices it should be performed based on the core gross profitability ratio. In this study we use both the retailers' mark-up in preand post-tax fuel prices. Furthermore, we maintain that weekly and, more importantly, 
monthly data may mask any asymmetric relationship, given that such price behaviour should not be expected to hold for lengthy time periods.

For the purpose of the current study, we use PLATTS price (as a proxy of import prices given that the cost of imported crude oil $(C I F)$ prices were not available at daily frequency) ${ }^{1}$, refined fuel prices, final pump prices for the unleaded 95 , as well as, the total tax imposed on the fuel prices. The data have been obtained from the Greek Ministry of Economy and Development and the period of study is from the $7^{\text {th }}$ January 2014 until 10 ${ }^{\text {th }}$ April 2018 (1267 daily observations). The data period is dictated by the data availability of the daily data. Table 2 and Figure 1 present the descriptive statistics of the data and their visual representation, respectively.

[TABLE 2 HERE]

\section{[FIGURE 1 HERE]}

From Table 2 it is evident the very high proportion of taxes to the retail fuel price, which, on average, is about $65.5 \%$. Another interesting observation from Table 2 is the fact that the variation in retail prices and retail mark-ups are materially lower compared to the refined fuel prices and refineries mark-up, respectively, as suggested by the coefficient of variation. This is rather interesting, suggesting that the refineries' prices are more volatile, although this is not clearly evident in Figure 1. Furthermore, it is important to note that the dispersion of PLATTS, refined fuel and retail prices differ, possibly suggesting that we should not anticipate a constant relationship among them. Figure 1 also confirms the high contribution of taxes in the final retail fuel prices.

\subsection{Methods}

We shall reiterate that, as shown in Section 1, the bulk literature assesses the (asymmetric) relationship between international crude oil prices and pump prices, using low frequency data (i.e. weekly or monthly). We opine that any asymmetry is not expected to be present in the longer run and thus low frequency data may mask the real relationship. Furthermore, these previous studies use crude oil and pump prices. More importantly, these studies tend to ignore the whole supply chain. This is suggestive of the fact that they make an implicit assumption that crude oil prices directly affect pump prices. We maintain that this may result in misleading findings.

\footnotetext{
${ }^{1}$ We opt to use the PLATTS prices rather than international crude oil prices due to the fact that oil transactions are taking place in the former (see, for instance, Balaguer and Ripollés, 2016).
} 
Thus, in this study we present a novel approach that can reveal the true relationships among international crude oil prices, refined fuel prices and pump prices.

Intentionally, and in order to provide evidence in favour of using the whole supply chain, we first follow the bulk of the literature presented in Section 1, starting our analysis by investigating the existence of asymmetric behaviour of retail prices to changes in international crude oil prices. Subsequently, we demonstrate how the results could differ if we consider the whole supply chain.

\subsubsection{Modelling Retailers' mark-up}

We denote $\left\{y_{t}^{(\text {ret })}\right\}_{t=1}^{T}$ and $\left\{y_{t}^{(\text {ret_tax })}\right\}_{t=1}^{T}$ the daily retailers' mark-up without and with the effect of taxation, respectively. For $y_{t}^{\left(r e t_{-} t a x\right)}=\frac{R p_{t}}{R_{t}+T f_{t}+T v_{t}}$ and $y_{t}^{(r e t)}=\frac{R p_{t}}{R_{t}}$ where, $R p_{t}, R_{t}, T f_{t}$, and $T v_{t}$, represent the daily retail gross profit, refined fuel prices, fixed taxation and variable taxation, respectively. The $R p_{t}=$ $P R_{t}-\left(R_{t}+T f_{t}+T v_{t}\right)$, with $P R_{t}$ denoting the after-tax retail fuel price.

We proceed to the estimation of the most recent days that the retailers' markups may be impacted by the PLATTS prices. The retailers order fuel at irregular days depending of the demand from the end users and the prices offered in the international crude oil market. Hence, we estimate the average PLATTS price of the $K$ most recent days that maximize the coefficient of determination for the relation between the deviations of the refined fuel prices and retailers' mark-up. Hence, we seek to estimate the following regression:

$$
y_{t}^{\left(r e t_{-} t a x\right)}=a_{0}+a_{1} I_{\left\{\bar{P}_{t}>\bar{P}_{t-1}\right\}}+u_{t},
$$

maximizing the following expression:

$$
\max _{K}\left(1-\frac{\sum_{t=1}^{T}\left(\widehat{u}_{t}^{2}\right)}{\sum_{t=1}^{T}\left(y_{t}^{(\text {ret_tax })}-\bar{y}^{(\text {ret_tax })}\right)^{2}}\right),
$$

where $\bar{y}^{(\text {ret_tax })}$ denotes the average retailers' mark-up including the taxation effect on the final fuel price. The $I_{\left\{\bar{P}_{t}>\bar{P}_{t-1}\right\}}$ denotes an indicator variable of the form:

$$
I_{\left\{\bar{P}_{t}>\bar{P}_{t-1}\right\}}=\left\{\begin{array}{lll}
0 & \text { if } & K^{-1} \sum_{k=1}^{K}\left(P_{t-k}\right)>K^{-1} \sum_{k=1}^{K}\left(P_{t-1-k}\right) \\
1 & \text { if } \quad K^{-1} \sum_{k=1}^{K}\left(P_{t-k}\right) \leq K^{-1} \sum_{k=1}^{K}\left(P_{t-1-k}\right)
\end{array},\right.
$$


with $P_{t}$ being the PLATTS prices, $\bar{P}_{t}=K^{-1} \sum_{k=1}^{K}\left(P_{t-k}\right)$ being the average PLATTS prices over $K$ days and $k>0^{2}$.

Naturally, we proceed with a numerical solution of the $\max _{K}($.$) , as an explicit$ closed form solution is not possible. The optimum number of the most recent days is $K=17$ for $\max _{K}()=.32.5 \%$ (see Figure 2 ).

\section{[FIGURE 2 HERE]}

Hence, we infer that overall retailers are affected by international crude oil prices, and subsequently form their mark-up, over the seventeen previous days. Based on the above, the estimated model is:

$$
\begin{gathered}
y_{t}^{(\text {ret_tax })}=\gamma_{0}+\gamma_{1} I_{\left\{\bar{P}_{t}>\bar{P}_{t-1}\right\} t}+\gamma_{2}\left(17^{-1} \sum_{k=1}^{17}\left(P_{t-k}\right)-\right. \\
\left.17^{-1} \sum_{k=1}^{17}\left(P_{t-1-k}\right)\right)+\gamma_{3} I_{\left\{\bar{P}_{t}>\bar{P}_{t-1}\right\}}\left(17^{-1} \sum_{k=1}^{17}\left(P_{t-k}\right)-\right. \\
\left.17^{-1} \sum_{k=1}^{17}\left(P_{t-1-k}\right)\right)+\varepsilon_{t},
\end{gathered}
$$

where we allow both the intercept and slope to differ between increases and decreases of $\bar{P}$, and $I_{\left\{\bar{P}_{t}>\bar{P}_{t-1}\right\}}=\left\{\begin{array}{lll}0 & \text { if } & \bar{P}_{t}>\bar{P}_{t-1} \\ 1 & \text { if } & \bar{P}_{t} \leq \bar{P}_{t-1}\end{array}\right.$ presents the indicator variable, for $K=17$.

Coefficient $\gamma_{0}$ shows the effects of the average PLATTS prices on retailers' mark-up and $\gamma_{2}$ indicates the effect of the difference in the average PLATTS prices between time $t$ and $t-1$. Equivalently, $\gamma_{0}+\gamma_{1}$ show the effect of decreasing average PLATTS prices, whereas $\gamma_{2}+\gamma_{3}$ denote the effects of decreasing average PLATTS prices at time $t$ relatively to time $t-1$.

Given our interest to assess also the effect of taxation on the abovementioned relationship, we further estimate the following regression:

$$
y_{t}^{(r e t)}=a_{0}+a_{1} I_{\left\{\bar{P}_{t}>\bar{P}_{t-1}\right\}}+u_{t},
$$

for $\max _{K}\left(1-\frac{\sum_{t=1}^{T}\left(\widehat{u}_{t}^{2}\right)}{\sum_{t=1}^{T}\left(y_{t}^{(r e t)}-\bar{y}^{(r e t)}\right)^{2}}\right)$, where, $\bar{y}^{(r e t)}$ denotes the average retailers' mark-up on the pre-tax fuel prices and $I_{\left\{\bar{P}_{t}>\bar{P}_{t-1}\right\}}$ presents the indicator variable, as previously.

\section{3. (A)symmetric behaviour of retailers to oil price changes}

The results for the retailers' mark-up, excluding and including the effect of taxation, are presented in Tables 3 and 4.

\section{[TABLES 3 and 4 HERE]}

\footnotetext{
${ }^{2}$ We do not consider $k=0$ since in such case both the right- and left-hand side variables would be simultaneously determined.
} 
Both tables provide the same findings, i.e. that retailers seem to follow a different pricing strategy depending on whether the 17-days moving average PLATTS prices are increasing or decreasing. In particular, irrespectively of the effect of taxation, the indicator variable is highly significant in both the constant and the slope. The positive and significant values of $\gamma_{1}$ coefficients suggest that when the average PLATTS prices are decreasing, the average retail fuel prices are higher (i.e. $\gamma_{0}<\gamma_{0}+$ $\left.\gamma_{1}\right) .^{3}$

Turning our attention to the slope, we observe that coefficient $\gamma_{2}$ is negative and statistically significant, whereas $\gamma_{3}$ is not significant. This is suggestive of the fact that retailers' mark-up does not change when the moving average of PLATTS prices at time $t$, relative to their moving average at time $t-1$, are higher.

Overall, these results clearly suggest that there is an asymmetric behaviour in the pricing strategy of retailers; where during low PLATTS price levels they tend to increase their mark-up significantly more compared to the higher PLATTS price levels. Even more, we observe that the exclusion of taxation does not alter our findings. Our results could suggest that they corroborate those of the existing literature, as discussed in Section 1.

More specifically, the results provide evidence in favour of the rockets and feathers hypothesis, whereby fuel prices tend to decline at a slower pace when international crude oil prices drop compared to their increase rate when oil prices increase. As Brown and Yucel (2000) suggest, there are various reasons why such asymmetry may exist, including, market concentration and market power in the retail fuel industry, consumers' reactions to changes in fuel prices or inventory management, among others. We note that it falls beyond the scope of the present study to assess which are the most important factors that apply to our case study of the Greek market. In any case, irrespectively of the drivers of asymmetry, our findings show that there is a loss in consumer welfare as a result of such retail price behaviour to decreases in international crude oil prices.

\footnotetext{
${ }^{3}$ We consider coefficient covariance estimators that are robust to the presence of heteroscedasticity, employing the method proposed by MacKinnon and White (1985) based on the seminal work of White (1980).
} 


\section{Re-modelling the relationship between crude oil and pump prices}

\subsection{Retailers' mark-up}

Section 3 provides evidence in favour of an asymmetric relationship between international crude oil prices (PLATTS) and pump prices. However, we need to make an important observation here. Retailers do not buy their fuel directly from the international crude oil market. Rather, they purchase their fuel from the refineries, hence the behaviour of their mark-up is more appropriately to be assessed based on the fluctuations of the refineries' fuel prices rather than the PLATTS prices.

So next, we re-estimate our models from Section 3 based on the retailers' mark-up, as a percentage of the refined fuel prices $\left(R_{t}\right)$. Based on the above, the estimated model, including the effect taxation is:

$$
\begin{gathered}
y_{t}^{(\text {ret_tax })}=\gamma_{0}+\gamma_{1} I_{\left\{\overline{R T}_{t}>\overline{R T}_{t-1}\right\} t}+\gamma_{2}\left(14^{-1} \sum_{k=1}^{14}\left(R_{t-k}+T f_{t-k}+T v_{t-k}\right)-\right. \\
\left.14^{-1} \sum_{k=1}^{14}\left(R_{t-1-k}+T f_{t-1-k}+T v_{t-1-k}\right)\right)+ \\
\gamma_{3} I_{\left\{\overline{R T}_{t}>\overline{R T}_{t-1}\right\}}\left(14^{-1} \sum_{k=1}^{14}\left(R_{t-k}+T f_{t-k}+T v_{t-k}\right)-14^{-1} \sum_{k=1}^{14}\left(R_{t-1-k}+\right.\right. \\
\left.\left.T f_{t-1-k}+T v_{t-1-k}\right)\right)+\varepsilon_{t},
\end{gathered}
$$

where, $R T_{t}=R_{t}+T f_{t}+T v_{t}$ is the refined fuel prices along with the taxes and $\overline{R T}_{t}=K^{-1} \sum_{k=1}^{K}\left(R T_{t-k}\right)$. The $R_{t}$ is the refined fuel price and $\bar{R}$ is the average refined fuel prices. The $I_{\left\{\overline{R T}_{t}>\overline{R T}_{t-1}\right\}}=\left\{\begin{array}{lll}0 & \text { if } & \overline{R T}_{t}>\overline{R T}_{t-1} \\ 1 & \text { if } & \overline{R T}_{t} \leq \overline{R T}_{t-1}\end{array}\right.$ presents the indicator variable, for $K=14$, as shown in Figure 3.

[FIGURE 3 HERE]

The estimated model, without the taxation effect, is:

$$
\begin{aligned}
y_{t}^{(r e t)}= & \delta_{0}+\delta_{1} I_{\left\{\bar{R}_{t}>\bar{R}_{t-1}\right\} t}+\delta_{2}\left(14^{-1} \sum_{k=1}^{14}\left(R_{t-k}\right)-14^{-1} \sum_{k=1}^{14}\left(R_{t-1-k}\right)\right)+ \\
& \delta_{3} I_{\left\{\bar{R}_{t}>\bar{R}_{t-1}\right\} t}\left(14^{-1} \sum_{k=1}^{14}\left(R_{t-k}\right)-14^{-1} \sum_{k=1}^{14}\left(R_{t-1-k}\right)\right)+\varepsilon_{t},
\end{aligned}
$$

where $I_{\left\{\bar{R}_{t}>\bar{R}_{t-1}\right\}}=\left\{\begin{array}{lll}0 & \text { if } & \bar{R}_{t}>\bar{R}_{t-1} \\ 1 & \text { if } & \bar{R}_{t} \leq \bar{R}_{t-1}\end{array}\right.$, for $K=14$. The results are shown in Tables 5 and 6.

\section{[TABLE 5 and 6 HERE]}

It is rather interesting that when we generate estimates based on the appropriate fuel prices (i.e. refined fuel prices rather than international crude oil prices - PLATTS), the retailers' asymmetric behaviour disappears, regardless the incorporate or exclusion of the taxation effect. This is evident by the insignificant coefficients $\gamma_{1}$ and $\gamma_{3}$ on Table 5 and $\delta_{1}$ and $\delta_{3}$ on Table 6. This is an important finding, as we 
convincingly show that unless the appropriate prices are considered in this line of enquiry, we may reveal misleading findings.

A reasonable question that follows is where the observed asymmetric behaviour, shown in Section 3, may rest, if not within the retail sector. Possibly, this asymmetry is evident at the previous stage of the supply chain. Hence, in the following section we test whether the asymmetric behaviour can be traced to the refineries.

\section{2 (A)symmetric behaviour of refineries to oil price changes}

To model refineries' behaviour, let us denote as $\left\{y_{t}^{(r e f)}\right\}_{t=1}^{T}$ the daily refineries' mark-up, for $y_{t}^{(\text {ref })}=\frac{R_{t}-P_{t}}{P_{t}}$, where $R_{t}$ and $P_{t}$ denote the daily refined fuel and PLATTS prices, respectively.

As in the case of retailers, refineries also buy oil at irregular days depending on the required amount and the offered prices. Hence, we estimate the average PLATTS price of the $K$ most recent days that maximize the coefficient of determination for the relationship between the deviations of the PLATTS prices and refineries' mark-up. Hence, we seek to maximise the following expression:

$$
\max _{K}\left(1-\frac{\sum_{t=1}^{T}\left(\hat{u}_{t}^{2}\right)}{\sum_{t=1}^{T}\left(y_{t}^{(r e f)}-\bar{y}^{(r e f)}\right)^{2}}\right),
$$

for the regression:

$$
y_{t}^{(r e f)}=a_{0}+a_{1} I_{\left\{\bar{P}_{t}>\bar{P}_{t-1}\right\}}+u_{t},
$$

where $I_{\left\{\bar{P}_{t}>\bar{P}_{t-1}\right\}}$ is the indicator variable denoted in section 2.2 .1 and $\bar{y}^{(r e f)}$ is the average refineries' mark-up.

The optimum number of the most recent days is $K=3$, for $\max _{K}()=.25.1 \%$, as it can be seen in Figure 4.

\section{[FIGURE 4 HERE]}

Hence, we infer that overall the refineries' purchase prices, and subsequently their mark-ups, are shaping up from the PLATTS prices of the three most recent days. Even though the number of days for the moving average calculation are endogenously identified, our finding closely matched with the sentiment of the Hellenic Petroleum Marketing Companies Association. The estimated model is: 


$$
\begin{aligned}
y_{t}^{(r e f)}= & \beta_{0}+\beta_{1} I_{\left\{\bar{P}_{t}>\bar{P}_{t-1}\right\}}+\beta_{2}\left(3^{-1} \sum_{k=1}^{3}\left(P_{t-k}\right)-3^{-1} \sum_{k=1}^{3}\left(P_{t-1-k}\right)\right)+ \\
& \beta_{3} I_{\left\{\bar{P}_{t}>\bar{P}_{t-1}\right\}}\left(3^{-1} \sum_{k=1}^{3}\left(P_{t-k}\right)-3^{-1} \sum_{k=1}^{3}\left(P_{t-1-k}\right)\right)+\varepsilon_{t},
\end{aligned}
$$

where $I_{\left\{\bar{P}_{t}>\bar{P}_{t-1}\right\}}=\left\{\begin{array}{lll}0 & \text { if } & \bar{P}_{t}>\bar{P}_{t-1} \\ 1 & \text { if } & \bar{P}_{t} \leq \bar{P}_{t-1}\end{array}\right.$ presents the indicator variable, for $K=3$.

The results for the refineries are shown in Table 7. The evidence presented from the model of equation 10 is rather clear. Even though the $\beta_{1}$ coefficient is not statistically significant, the $\beta_{3}$ coefficient is highly significant and negative. Thus, we show that when the moving average PLATTS at time $t$ relative to their moving average at time $t-1$ are lower during the low PLATTS price levels, then the refineries' mark-up tends to increase even faster, compared to the same behaviour during the high PLATTS price levels (i.e. $\beta_{2}<\beta_{2}+\beta_{3}$, based on the opposite signs).

These results clearly suggest that there is an asymmetric behaviour in the pricing strategy of refineries; where, during decreasing PLATTS price levels they tend to increase their mark-up significantly more compared to the increasing PLATTS price levels. Such asymmetric behaviour could be the result of market concentration and market power in the refining sector (which could lead to oligopolistic practices) or possibly to the cost structure of the industry. The end result, though, is that such asymmetric behaviour leads to consumer welfare loss when the international oil prices are pushed downwards.

\section{[TABLE 7 HERE]}

Figures 5 and 6 corroborate our findings from Table 7. In Figure 5 we depict the symmetric behaviour between the refineries' mark-up and the PLATTS price changes. It is evident that there is a negative relationship, yet we cannot clearly distinguish whether this relationship has a different behaviour during decreasing and increasing PLATTS price levels. The latter is exhibited in Figure 6. It is rather clear that the slope in the lower panel of Figure 6 (which is the decreasing PLATTS price levels) is steeper compared to the slope in the upper panel. Even more, the refineries' mark-up levels are also higher in the lower panel (see y-axes).

[FIGURES 5 and 6 HERE]

\section{Robustness tests}

For robustness and comparative purpose, we run the same models as in Section 4.2, using weekly and monthly data, which are the most common data 
sampling frequencies used by the existing studies. The results are shown in Table 8 . We have estimated the models for the refineries only, since this is where we have identified the asymmetric behavior. We estimate the model in equation 10 at both weekly and monthly frequencies. For additional robustness, we convert the daily data into weekly and monthly using both the last daily observation of the week or month, as well as, the average daily prices of the week or month.

\section{[TABLE 8 HERE]}

The results clearly show that the evidence of asymmetric behavior disappears when we use the data at a lower sampling frequency (all $\beta_{1}$ and $\beta_{3}$ coefficients that are reported on Table 8 are statistically insignificant, with the exception of the $\beta_{3}$ coefficient on the weekly frequency at the lower part of Table 8). Therefore, our findings clearly suggest that using lower sampling frequencies (i.e. lower than daily), which is rather common in the existing literature, is not the adequate approach to identify the possible asymmetries. The asymmetric effect is a short run phenomenon, so the lower frequency analysis masks this. This finding also suggests that modelling frameworks which are directed to test long run equilibrium such as asymmetric error correction or threshold cointegration models should not be used unless the short run relationship is first examined.

So far, we distinguish between positive and negative changes in crude oil or refinery prices so as to assess the asymmetric behaviour of retailer and refineries. However, it is possible that there may also be non-zero threshold parameters. In such case, the potential asymmetric responses will be both sign and size dependent. To assess such possibility, we develop a framework that accounts for a nonzero threshold parameter in order to distinguish between asymmetric changes in crude oil (or refinery prices); i.e. non only symmetric changes around zero. The optimal value of the threshold parameter can be iteratively determined by conducting a grid search and i) either minimizing the sum of the squared residuals ii) or maximizing the likelihood function or any other goodness of fitness function, such as the function that we have utilized in the paper.

So, we proceed to the estimation of the following regression for the identification of the retailers' asymmetric behavior:

$$
y_{t}^{(\text {ret_tax })}=a_{0}+a_{1} I_{\left\{\bar{P}_{t}-\bar{P}_{t-1}>\omega\right\}}+u_{t},
$$

by maximizing the expression: 


$$
\max _{K, \omega}\left(1-\frac{\sum_{t=1}^{T}\left(\widehat{u}_{t}^{2}\right)}{\sum_{t=1}^{T}\left(y_{t}^{(\text {ret_tax })}-\bar{y}^{(\text {ret_tax })}\right)^{2}}\right),
$$

where $I_{\left\{\bar{P}_{t}-\bar{P}_{t-1}>\omega\right\}}$ denotes an indicator variable of the form:

$$
I_{\left\{\bar{P}_{t}-\bar{P}_{t-1}>\omega\right\}}=\left\{\begin{array}{lll}
0 & \text { if } & K^{-1} \sum_{k=1}^{K}\left(P_{t-k}\right)-K^{-1} \sum_{k=1}^{K}\left(P_{t-1-k}\right)>\omega \\
1 & \text { if } & K^{-1} \sum_{k=1}^{K}\left(P_{t-k}\right)-K^{-1} \sum_{k=1}^{K}\left(P_{t-1-k}\right) \leq \omega .
\end{array}\right.
$$

The $\bar{y}^{\text {(ret_tax) }}$ denotes the average retailers' mark-up including the taxation effect on the final fuel price, $P_{t}$ are the PLATTS prices, $\bar{P}_{t}=K^{-1} \sum_{k=1}^{K}\left(P_{t-k}\right)$ is the average PLATTS prices over $\mathrm{K}$ days. The threshold parameter $\omega$ is incorporated in order to distinguish between asymmetric changes in PLATTS prices. As an explicit closed form solution for $\max _{K, \omega}($.$) is not possible, we proceed with its numerical$ solution conducting a grid search.

The optimum number of the most recent days is $K=25$ and the threshold parameter is $\omega=-0,0006$ for $\max _{K, \omega}()=.33.6 \%$. Figure $A 1$, in the appendix, plots the heat map of the grid search for various values of $K$ and $\omega$. Tables A1 and A2, in the appendix, present the estimated models for the retailers' mark-up, excluding and including the effect of taxation.

Both tables provide similar findings with the models presented in Section 3. Hence, when we assume for asymmetric changes in PLATTS prices, the threshold parameter equals to $\omega=-0,0006$ providing a $\max _{K, \omega}()=.33.6 \%$, which is very close to $\max _{K}()=.32.5 \%$. So, even when we account for a nonzero threshold parameter, our findings are similar with Tables 3 and 4.

Regarding the models based on the retailers' mark-up, as a percentage of the refined fuel prices $\left(R_{t}\right)$, we proceed to the estimation of the regression:

$$
y_{t}^{(\text {ret_tax })}=a_{0}+a_{1} I_{\left\{\overline{R T} t-\overline{R T}_{t-1}>\omega\right\}}+u_{t},
$$

by maximizing the expression:

$$
\max _{K, \omega}\left(1-\frac{\sum_{t=1}^{T}\left(\widehat{u}_{t}^{2}\right)}{\sum_{t=1}^{T}\left(y_{t}^{(\text {ret_tax })}-\bar{y}^{(\text {ret_tax })}\right)^{2}}\right),
$$

where $I_{\left\{\overline{R T}_{t}-\overline{R T}_{t-1}>\omega\right\}}$ denotes an indicator variable of the form: 


$$
I_{\left\{\overline{R T}_{t}-\overline{R T}_{t-1}>\omega\right\}}=\left\{\begin{array}{lll}
0 & \text { if } & \overline{R T}_{t}-\overline{R T}_{t-1}>\omega \\
1 & \text { if } & \overline{R T}_{t}-\overline{R T}_{t-1} \leq \omega .
\end{array}\right.
$$

The $R T_{t}=R_{t}+T f_{t}+T v_{t}$ is the refined fuel prices along with the taxes and $\overline{R T}_{t}=K^{-1} \sum_{k=1}^{K}\left(R T_{t-k}\right)$. The optimum number of the most recent days is $K=20$ and the estimated threshold parameter equals to $\omega=-0,0002$ for $\max _{K, \omega}()=.32.6 \%$. Figure A2 plots the heat map of the grid search for various values of $K$ and $\omega$. Tables A3 and A4, in the appendix, present the estimated models for the retailers' mark-up, including and excluding the effect of taxation. Both tables provide similar findings with the models presented in Section 4 (see Tables 5 and 6). Hence, when we assume for asymmetric changes in the refined fuel prices, those asymmetries are almost indistinguishable; the threshold parameter equals to $\omega=-0,0002$ almost equal to zero, providing a $\max _{K, \omega}()=.32.6 \%$, which is very close to $\max _{K}()=.31.5 \%$.

Finally, we focus on the refineries' asymmetric behavior, seeking to maximise:

$$
\max _{K, \omega}\left(1-\frac{\sum_{t=1}^{T}\left(\hat{u}_{t}^{2}\right)}{\sum_{t=1}^{T}\left(y_{t}^{(r e f)}-\bar{y}^{(r e f)}\right)^{2}}\right),
$$

for the regression:

$$
y_{t}^{(r e f)}=a_{0}+a_{1} I_{\left\{\bar{P}_{t}-\bar{P}_{t-1}>\omega\right\}}+u_{t},
$$

where

$$
I_{\left\{\bar{P}_{t}-\bar{P}_{t-1}>\omega\right\}}=\left\{\begin{array}{ccc}
0 & \text { if } & K^{-1} \sum_{k=1}^{K}\left(P_{t-k}\right)-K^{-1} \sum_{k=1}^{K}\left(P_{t-1-k}\right)>\omega \\
1 & \text { if } & K^{-1} \sum_{k=1}^{K}\left(P_{t-k}\right)-K^{-1} \sum_{k=1}^{K}\left(P_{t-1-k}\right) \leq \omega .
\end{array}\right.
$$

The optimum number of the most recent days is $K=25$ and the estimated threshold parameter equals to $\omega=-0,0008$ for $\max _{K, \omega}()=.26.5 \%$. Figure A3 plots the heat map of the grid search for various values of $K, \omega$. Table A5 presents the estimated models for the refineries' mark-up based on PLATTS prices, which corroborate the findings presented in Table 7. Hence, when we assume for asymmetric changes in PLATTS prices, the threshold parameter equals to $\omega=$ $-0,0008$, providing a $\max _{K, \omega}()=.26.5 \%$, which is very close to $\max _{K}()=.25.1 \%$. 
Once again, even when we account for a nonzero threshold parameter, our findings remain robust.

\section{Concluding remarks}

The aim of this paper is to assess the potential asymmetric behaviour of pump prices on increasing and decreasing crude oil prices, employing a novel approach. In particular, unlike the bulk of the existing literature, we consider the whole supply chain in order to discover whether and at which stage such asymmetric behaviour may exist. Even more, we depart from the practice of the existing literature that focuses on the actual fuel prices, but rather we focus on the refineries' and retailers' mark-ups based on the premise that any asymmetric behaviour should be evident in the pricing strategy of these two stakeholders. Our case study is the Greek downstream sector due to the availability of the unique dataset.

Overall, our findings based on daily data show that the fuel retailers do not change their mark-up behaviour based on increasing or decreasing refined fuel price. By contrast, refineries' mark-up changes relatively to changes in the crude oil prices, which is suggestive of an asymmetric behaviour that is then passed through to the retailers and consumers.

Systematic asymmetry in price adjustments could have negative consequences for the economy as a whole and a continuing deterioration of consumers' purchasing power to the benefit of producers/suppliers.

It is mentioned that the Greek gasoline market is characterised by high concentration, since there exist two companies in the refining sector, four large companies in the wholesale market (which have a market share of more than $50 \%$ ) and each of them has a nationwide network of fuel stations. The structure of the oil market in Greece has also been the topic of monitoring and research in a number of reports of the Hellenic Competition Commission (HCC), which repetitively stated the need for further liberalisation of the market (see, for instance, Hellenic Competition Commission, 2012). It has also been subject of policy recommendations by international organizations (such as, OECD, 2017) and by institutions, such as the International Monetary Fund, the European Commission and the European Central Bank (see, for example, Memorandum of Understanding, 2015).

For the Greek gasoline market, it is crucial that the competition authorities monitor the market, in particular the $\mathrm{HCC}$ to ensure competitive operation to the 
greatest possible extent (see also Balaguer and Ripolles, 2012, Polemis and Fotis, 2013 and Asane-Otoo and Schneider, 2015 for similar policy implications). This becomes even more crucial in periods of recession, as the Greek economy dramatically faced over the past decade, when consumers have to deal with a general decline in their income level and living standards. The matter has additional implications in economies with a high concentration of suppliers, who have high market power and could, thus, abuse their dominant position.

The paper provides a robust empirical evidence of an asymmetric behaviour of the refineries' mark-up changes relatively to changes in the crude oil prices for the Greek gasoline market. This evidence of asymmetric behaviour from the side of refiners should be taken into account from the HCC. A systematic monitoring of the market conditions and regulations by the $\mathrm{HCC}$ is required, which should focus on the practices of the refineries' companies in order to ensure price transparency and prevent, if any, oligopolistic practices.

We further highlight that the use of weekly and monthly data mask this asymmetric relationship. Also, we convincingly show that unless the appropriate fuel price transformation is considered (i.e. mark-ups), we may reveal misleading findings. Thus, our results certainly provide new insights on how to investigate the effects of international crude oil prices on refined and retail fuel prices.

We should note that the input and output prices for the refining sector refer to different products (i.e. crude oil versus unleaded fuel). However, refineries are multiproduct firms, producing unleaded fuel, diesel and kerosene, among others. Therefore, apart from the crude oil prices, it could be also the case that the conditions of the other fuel markets also impact their mark-up on the unleaded fuel. This is an issue worth exploring in future work. Further research could also investigate the main drivers of the asymmetric behaviour of refineries mark-up to changes in international crude oil prices so to identify whether such behaviour is led by speculation, collusive behaviour or due to the cost structure of refineries. Another interesting avenue for further study could constitute the identification of asymmetric behaviour based on a time-varying framework, as well as, based on disaggregated data on individual petrol stations, which are scattered around different geographical locations and have different ownership structures. Finally, similar econometric frameworks should be employed to additional countries since the potential asymmetric behaviour by refineries or retailers is a global issue. 


\section{Acknowledgements:}

The authors would like to thank the handling editor (Russel Smyth) and the anonymous referees for their invaluable comments and suggestions on this paper. We would also like to thank Heather Gibson for her constructive comments on a previous version of our work. Furthermore, special thanks are owed to Markos Petroulakis and Aggelos Degiannakis from the Ministry of Economic Development for providing part of the data that were used in this paper. This research was conducted while George Filis was visiting Bank of Greece on the Bank's programme of cooperation with universities. The views expressed are our own and not necessarily shared by the institutions we are affiliated with. The usual disclaimer applies.

\section{References}

Angelopoulou, E., \& Gibson, H. D. (2010). The determinants of retail petrol prices in Greece. Economic Modelling, 27(6), 1537-1542.

Apergis, N., \& Vouzavalis, G. (2018). Asymmetric pass through of oil prices to gasoline prices: Evidence from a new country sample. Energy Policy, 114, 519528.

Asane-Otoo, E., \& Schneider, I. (2015). Retail fuel price adjustment in Germany: A threshold cointegration approach, Energy Policy, 78, 1-10.

Bachmeier, L. J., \& Griffin, J. M. (2003). New evidence on asymmetric gasoline price responses. Review of Economics and Statistics, 85(3), 772-776.

Bacon, R. W. (1991). Rockets and feathers: the asymmetric speed of adjustment of UK retail gasoline prices to cost changes. Energy Economics, 13(3), 211-218.

Balaguer, J., \& Ripollés, J. (2012). Testing for price response asymmetries in the Spanish fuel market. New evidence from daily data. Energy Economics, 34(6), 2066-2071.

Balaguer, J., \& Ripollés, J. (2016). Asymmetric fuel price responses under heterogeneity. Energy Economics, 54, 281-290.

Balke, N. S., Brown, S. P., \& Yucel, M. K. (1998). Crude oil and gasoline prices: an asymmetric relationship? Economic Review, Federal Reserve Bank of Dallas, 2.

Bermingham, C., \& O'Brien, D. (2011). Testing for asymmetric pricing behaviour in Irish and UK petrol and diesel markets. The Energy Journal, 1-26.

Bettendorf, L., Van der Geest, S. A., \& Varkevisser, M. (2003). Price asymmetry in the Dutch retail gasoline market. Energy Economics, 25(6), 669-689. 
Blair, B. F., Campbell, R. C., \& Mixon, P. A. (2017). Price pass-through in US gasoline markets. Energy Economics, 65, 42-49.

Borenstein, S., Cameron, A. C., \& Gilbert, R. (1997). Do gasoline prices respond asymmetrically to crude oil price changes?. The Quarterly Journal of Economics, 112(1), 305-339.

Boroumand, R. H., Goutte, S., Porcher, S., \& Porcher, T. (2016). Asymmetric evidence of gasoline price responses in France: A Markov-switching approach. Economic Modelling, 52, 467-476.

Bragoudakis, Z., \& Sideris, D. (2012). Do retail gasoline prices adjust symmetrically to crude oil price changes? The case of the Greek oil market. Economic Bulletin, 37, 7-21.

Brown, S. P., \& Yucel, M. K. (2000). Gasoline and crude oil prices: why the asymmetry? Economic and Financial Review, 23.

Buyuksahin, B., \& Robe, M. A. (2014). Speculators, commodities and cross-market linkages. Journal of International Money and Finance, 42, 38-70.

Chang, D., \& Serletis, A. (2016). Oil, uncertainty, and gasoline prices. Macroeconomic Dynamics, 22(3), 546-561.

Cook, S., \& Fosten, J. (2018). Replicating rockets and feathers. Energy Economics. Online first.

Delpachitra, S. B. (2002). Price rigidity in the downstream petroleum industry in New Zealand: where does it happen? Energy Economics, 24(6), 597-613.

Douglas, C. C. (2010). Do gasoline prices exhibit asymmetry? Not usually! Energy Economics, 32(4), 918-925.

Duffy-Deno, K. T. (1996). Retail price asymmetries in local gasoline markets. Energy Economics, 18(1-2), 81-92.

Eleftheriou, K., Nijkamp, P., \& Polemis, M. L. (2018). Asymmetric price adjustments in US gasoline markets: impacts of spatial dependence on the 'rockets and feathers' hypothesis. Regional Studies, 1-14.

Galeotti, M., Lanza, A., \& Manera, M. (2003). Rockets and feathers revisited: an international comparison on European gasoline markets. Energy Economics, 25(2), 175-190

Gautier, E., \& Saout, R. L. (2015). The dynamics of gasoline prices: Evidence from daily French micro data. Journal of Money, Credit and Banking, 47(6), $1063-$ 1089. 
Godby, R., Lintner, A.M., Stengos, T., \& Wandschneider, B. (2000). Testing for asymmetric pricing in the Canadian retail gasoline market. Energy Economics, 22(3), 349-368.

Grasso, M., \& Manera, M. (2007). Asymmetric error correction models for the oilgasoline price relationship. Energy Policy, 35(1), 156-177.

Hellenic Competition Commission (2012). Opinion (based on article 23, Law $3959 / 2011$ ) on the effectiveness of the lifting of restrictions and regulations on the oil products sector.

Kang, W., de Gracia, F.P., \& Ratti, R. A. (2018). The asymmetric response of gasoline prices to oil price shocks and policy uncertainty. Energy Economics. Online first.

Karagiannis, S., Panagopoulos, Y., \& Vlamis, P. (2015). Are unleaded gasoline and diesel price adjustments symmetric? A comparison of the four largest EU retail fuel markets. Economic Modelling, 48, 281-291.

Kaufmann, R.K., \& Laskowski, C. (2005). Causes for an asymmetric relation between the price of crude oil and refined petroleum products. Energy Policy, 33(12), 1587-1596.

Kilian, L. (2010). Explaining fluctuations in gasoline prices: a joint model of the global crude oil market and the US retail gasoline market. The Energy Journal, 87-112.

Kirchgässner, G., \& Kübler, K. (1992). Symmetric or asymmetric price adjustments in the oil market: an empirical analysis of the relations between international and domestic prices in the Federal Republic of Germany, 1972-1989. Energy Economics, 14(3), 171-185.

Kristoufek, L., \& Lunackova, P. (2015). Rockets and feathers meet Joseph: Reinvestigating the oil-gasoline asymmetry on the international markets. Energy Economics, 49, 1-8.

Lahiani, A., Miloudi, A., Benkraiem, R., \& Shahbaz, M. (2017). Another look on the relationships between oil prices and energy prices. Energy Policy, 102, 318331.

Le Pen, Y., \& Sévi, B. (2017). Futures trading and the excess co-movement of commodity prices. Review of Finance, 22(1), 381-418. 
Liu, M. H., Margaritis, D., \& Tourani-Rad, A. (2010). Is there an asymmetry in the response of diesel and petrol prices to crude oil price changes? Evidence from New Zealand. Energy Economics, 32(4), 926-932.

MacKinnon, J.G. and H. White (1985). Some Heteroskedasticity Consistent Covariance Matrix Estimators with Improved Finite Sample Properties, Journal of Econometrics, 29, 53-57.

Manning, D. N. (1991). Petrol prices, oil price rises and oil price falls: some evidence for the UK since 1972. Applied Economics, 23(9), 1535-1541.

Memorandum of Understanding (2015). Greece: Memorandum of Understanding on Specific Economic Policy Conditionality, August.

Meyler, A. (2009). The pass through of oil prices into euro area consumer liquid fuel prices in an environment of high and volatile oil prices. Energy Economics, $31(6), 867-881$.

Oladunjoye, O. (2008). Market structure and price adjustment in the US wholesale gasoline markets. Energy Economics, 30(3), 937-961.

OECD (2017). Competition assessment reviews: Greece.

https://www.oecd.org/publications/oecd-competition-assessment-reviewsgreece-2017-9789264088276-en.htm

Panagiotidis, T., \& Rutledge, E. (2007). Oil and gas markets in the UK: Evidence from a cointegrating approach. Energy Economics, 29(2), 329-347.

Perdiguero-García, J. (2013). Symmetric or asymmetric oil prices? A meta-analysis approach. Energy policy, 57, 389-397.

Polemis, M. L. (2012). Competition and price asymmetries in the Greek oil sector: an empirical analysis on gasoline market. Empirical Economics, 43(2), 789-817.

Polemis, M., L., \& Fotis, P. (2013). Do gasoline prices respond asymmetrically in the euro zone area? Evidence from cointegrated panel data analysis, Energy Policy, 56, 425-433.

Qin, X., Zhou, C., \& Wu, C. (2016). Revisiting asymmetric price transmission in the US oil-gasoline markets: A multiple threshold error-correction analysis. Economic Modelling, 52, 583-591.

Radchenko, S. (2005). Oil price volatility and the asymmetric response of gasoline prices to oil price increases and decreases. Energy economics, 27(5), 708-730. 
Radchenko, S., \& Shapiro, D. (2011). Anticipated and unanticipated effects of crude oil prices and gasoline inventory changes on gasoline prices. Energy Economics, 33(5), 758-769.

Rahman, S. (2016). Another perspective on gasoline price responses to crude oil price changes. Energy Economics, 55, 10-18.

Sen, A. (2003). Higher prices at Canadian gas pumps: international crude oil prices or local market concentration? An empirical investigation. Energy Economics, 25(3), 269-288.

Shin, D. (1994). Do product prices respond symmetrically to changes in crude prices? OPEC Review, 18(2), 137-157.

Valadkhani, A., Smyth, R., \& Vahid, F. (2015). Asymmetric pricing of diesel at its source. Energy Economics, 52, 183-194.

White, H. (1980). A Heteroskedasticity-Consistent Covariance Matrix and a Direct Test for Heteroskedasticity, Econometrica, 48, 817-838. 
TABLES

\begin{tabular}{|c|c|c|c|c|}
\hline Authors (year) & Method & Frequency & $\begin{array}{l}\text { Symmetric or Asymmetric effects } \\
\text { to oil price changes? }\end{array}$ & Country \\
\hline Apergis and Vouzavalis (2018) & $\begin{array}{l}\text { Non-linear auto- } \\
\text { regressive } \\
\text { distributed lags }\end{array}$ & Monthly & $\begin{array}{l}\text { Symmetric and asymmetric } \\
\text { responses to oil price changes, } \\
\text { depending on the country }\end{array}$ & $\begin{array}{l}\text { Italy, Spain, } \\
\text { Greece, UK, } \\
\text { US }\end{array}$ \\
\hline Blair et al. (2017) & ECM & Weekly & $\begin{array}{l}\text { Asymmetric responses to oil price } \\
\text { changes }\end{array}$ & US regions \\
\hline Boroumand et al. (2016) & $\begin{array}{l}\text { Markov-switching } \\
\text { regression and } \\
\text { MS-ECM }\end{array}$ & Weekly & $\begin{array}{l}\text { Asymmetric responses to oil price } \\
\text { changes }\end{array}$ & France \\
\hline Chang and Serletis (2016) & $\begin{array}{l}\text { Structural } \\
\text { GARCH-in-Mean } \\
\text { VAR }\end{array}$ & Monthly & $\begin{array}{l}\text { Asymmetric responses to oil price } \\
\text { changes }\end{array}$ & US \\
\hline Eleftheriou et al. (2018) & $\begin{array}{l}\text { Asymmetric } \\
\text { spatial error } \\
\text { correction model }\end{array}$ & Daily & $\begin{array}{l}\text { Asymmetric responses to oil price } \\
\text { changes }\end{array}$ & US \\
\hline Karagiannis et al. (2015) & ECM & Weekly & $\begin{array}{l}\text { Symmetric responses to oil price } \\
\text { changes }\end{array}$ & $\begin{array}{l}\text { EU } \\
\text { countries }\end{array}$ \\
\hline Kilian (2010) & SVAR & Monthly & $\begin{array}{l}\text { Asymmetric responses to oil price } \\
\text { shocks }\end{array}$ & US \\
\hline Kristoufek and Lunackova (2015) & $\begin{array}{l}\text { ECM, VAR, TAR- } \\
\text { ECM }\end{array}$ & Weekly & $\begin{array}{l}\text { Symmetric responses to oil price } \\
\text { changes }\end{array}$ & $\begin{array}{l}\text { Various EU } \\
\text { countries } \\
\text { and US }\end{array}$ \\
\hline Liu et al. (2010) & ECM & Weekly & $\begin{array}{l}\text { Asymmetric responses to oil price } \\
\text { changes }\end{array}$ & $\begin{array}{l}\text { New } \\
\text { Zealand }\end{array}$ \\
\hline
\end{tabular}




\begin{tabular}{|c|c|c|c|c|}
\hline Meyler (2009) & VECM & Weekly & $\begin{array}{l}\text { Symmetric responses to oil price } \\
\text { changes }\end{array}$ & EU \\
\hline Qin et al. (2016) & $\begin{array}{l}\text { Multiple threshold } \\
\text { error-correction } \\
\text { model }\end{array}$ & Weekly & $\begin{array}{l}\text { Asymmetric responses to oil price } \\
\text { changes }\end{array}$ & US \\
\hline Radchenko (2005) & VAR & Monthly & $\begin{array}{l}\text { Asymmetric responses to oil price } \\
\text { volatility }\end{array}$ & US \\
\hline Radchenko and Shapiro (2011) & ECM, VAR & Weekly & $\begin{array}{l}\text { Asymmetric responses to oil price } \\
\text { changes }\end{array}$ & US \\
\hline Rahman (2016) & $\begin{array}{l}\text { GARCH(1,1)-in- } \\
\text { Mean SVAR }\end{array}$ & Monthly & $\begin{array}{l}\text { Asymmetric responses to oil price } \\
\text { changes }\end{array}$ & US \\
\hline Sen (2003) & Panel regression & Monthly & $\begin{array}{l}\text { Symmetric responses to oil price } \\
\text { changes }\end{array}$ & Canada \\
\hline Valadkhani et al. (2015) & $\begin{array}{l}\text { Dynamic Least } \\
\text { Squares and } \\
\text { VECM }\end{array}$ & Weekly & $\begin{array}{l}\text { Asymmetric responses to oil price } \\
\text { changes }\end{array}$ & Australia \\
\hline
\end{tabular}




\begin{tabular}{|c|c|c|c|c|}
\hline \multicolumn{5}{|c|}{ Table 2: Descriptive statistics } \\
\hline & PLATTS & REFINED PRICE & RETAIL_PRICE_AT & TOTAL_TAXES \\
\hline Mean & 0.3960 & 0.4219 & 1.5086 & 0.9829 \\
\hline Median & 0.3871 & 0.4124 & 1.5120 & 0.9938 \\
\hline Maximum & 0.5916 & 0.6259 & 1.7140 & 1.0330 \\
\hline Minimum & 0.2314 & 0.2604 & 1.2960 & 0.9205 \\
\hline Std. Dev. & 0.0695 & 0.0707 & 0.0943 & 0.0316 \\
\hline Coeff. Var. & 0.1755 & 0.1675 & 0.0625 & 0.0321 \\
\hline \multirow[t]{2}{*}{ Observations } & 1267 & 1267 & 1267 & 1267 \\
\hline & REFINERIES_MARK_UP & RETAIL_MARK_UP_PT & RETAIL_MARK_UP_AT & \\
\hline Mean & 0.0674 & 0.2534 & 0.0742 & \\
\hline Median & 0.0635 & 0.2473 & 0.0738 & \\
\hline Maximum & 0.2321 & 0.4895 & 0.1133 & \\
\hline Minimum & 0.0030 & 0.1320 & 0.0429 & \\
\hline Std. Dev. & 0.0293 & 0.0546 & 0.0101 & \\
\hline Coeff. Var. & 0.4347 & 0.2154 & 0.1361 & \\
\hline Observations & 1267 & 1267 & 1267 & \\
\hline
\end{tabular}

\section{Table 3: Retailers' mark-up (excluding taxes) based} on PLATTS prices.

\begin{tabular}{lrrr}
\hline & Coefficient & Std. Error & Prob. \\
\cline { 2 - 4 }$\gamma_{0}$ (Constant) & 0.0733 & 0.0004 & 0.0000 \\
$\gamma_{1}$ (Dummy) & 0.0021 & 0.0006 & 0.0005 \\
$\gamma_{2}$ (Slope) & -3.5739 & 0.2425 & 0.0000 \\
$\gamma_{3}$ (Slope*Dummy) & 0.3341 & 0.3452 & 0.3334 \\
Adjusted R-squared & & 0.4748 & \\
F-statistic & & 375.3115 & \\
Prob(F-statistic) & & 0.0000 & \\
\hline
\end{tabular}

Note: HAC heteroscedasticity and autocorrelation robust standard errors are used. 


\begin{tabular}{|c|c|c|c|}
\hline & Coefficient & Std. Error & Prob. \\
\hline$\gamma_{0}$ (Constant) & 0.2485 & 0.0025 & 0.0000 \\
\hline$\gamma_{1}$ (Dummy) & 0.0111 & 0.0038 & 0.0039 \\
\hline$\gamma_{2}($ Slope $)$ & -12.8010 & 1.4644 & 0.0000 \\
\hline$\gamma_{3}$ (Slope*Dummy) & 0.3328 & 2.0626 & 0.8718 \\
\hline Adjusted R-squared & & 0.2507 & \\
\hline F-statistic & & 138.9098 & \\
\hline Prob(F-statistic) & & 0.0000 & \\
\hline
\end{tabular}

\begin{tabular}{|c|c|c|c|}
\hline \multicolumn{4}{|c|}{$\begin{array}{l}\text { Table 5: Retailers' mark-up (including taxes) based } \\
\text { on REFINED fuel prices. }\end{array}$} \\
\hline & Coefficient & Std. Error & Prob. \\
\hline$\gamma_{0}($ Constant $)$ & 0.0733 & 0.0009 & 0.0000 \\
\hline$\gamma_{1}$ (Dummy) & 0.0019 & 0.0012 & 0.1056 \\
\hline$\gamma_{2}$ (Slope) & -3.4644 & 0.4765 & 0.0000 \\
\hline$\gamma_{3}$ (Slope*Dummy) & 0.3666 & 0.7401 & 0.6204 \\
\hline Adjusted R-squared & \multicolumn{3}{|c|}{04691} \\
\hline F-statistic & \multicolumn{3}{|c|}{367.5691} \\
\hline $\operatorname{Prob}($ F-statistic) & \multicolumn{3}{|c|}{0.0000} \\
\hline
\end{tabular}

Table 6: Retailers' mark-up (excluding taxes) based on REFINED fuel prices.

\begin{tabular}{lrrr} 
& \multicolumn{1}{c}{ Coefficient } & Std. Error & Prob. \\
\cline { 2 - 4 }$\delta_{0}$ (Constant) & 0.2479 & 0.0059 & 0.0000 \\
$\delta_{1}$ (Dummy) & 0.0103 & 0.0074 & 0.1645 \\
$\delta_{2}$ (Slope) & -12.2703 & 3.0918 & 0.0000 \\
$\delta_{3}$ (Slope*Dummy) & -0.4385 & 4.6852 & 0.9254 \\
Adjusted R-squared & & 0.2603 & \\
F-statistic & & 146.4145 & \\
Prob(F-statistic) & & 0.0000 & \\
\hline
\end{tabular}

Note: HAC heteroscedasticity and autocorrelation robust standard errors are used. 
Table 7: Refineries' mark-up based on PLATTS prices.

\begin{tabular}{lrrr}
\hline & Coefficient & Std. Error & Prob. \\
\cline { 2 - 4 }$\beta_{0}$ (Constant) & 0.0637 & 0.0015 & 0.0000 \\
$\beta_{1}$ (Dummy) & 0.0023 & 0.0022 & 0.2996 \\
$\beta_{2}$ (Slope) & -3.7042 & 0.3144 & 0.0000 \\
$\beta_{3}$ (Slope*Dummy) & -1.4983 & 0.6436 & 0.0201 \\
Adjusted R-squared & & 0.7347 \\
F-statistic & \multicolumn{3}{c}{1162.1230} \\
Prob(F-statistic) & 0.0000 \\
\hline Note: HAC heteroscedasticity and autocorrelation robust standard \\
errors are used.
\end{tabular}

Table 8: Analysis at weekly and monthly frequency: Refineries' mark-up based on PLATTS prices.

\begin{tabular}{|c|c|c|c|c|c|c|}
\hline & \multicolumn{3}{|c|}{ Weekly } & \multicolumn{3}{|c|}{ Monthly } \\
\hline & \multicolumn{6}{|c|}{ Last observation } \\
\hline & Coefficient & Std. Error & Prob. & Coefficient & Std. Error & Prob. \\
\hline$\beta_{0}$ (Constant) & 0.0693 & 0.0039 & 0.0000 & 0.0627 & 0.0006 & 0.0000 \\
\hline$\beta_{1}$ (Dummy) & -0.0045 & 0.0056 & 0.4186 & 0.0101 & 0.0062 & 0.1114 \\
\hline$\beta_{2}$ (Slope) & -0.0508 & 0.1842 & 0.7829 & -0.0286 & 0.1608 & 0.8597 \\
\hline$\beta_{3}$ (Slope*Dummy) & -0.1551 & 0.2910 & 0.5946 & 0.0224 & 0.2344 & 0.9241 \\
\hline Adjusted R-squared & & -0.0064 & & & 0.0531 & \\
\hline F-statistic & & 0.5291 & & & 1.9173 & \\
\hline \multirow[t]{4}{*}{ Prob(F-statistic) } & & 0.6627 & & & 0.1399 & \\
\hline & \multicolumn{3}{|c|}{ Weekly } & \multicolumn{3}{|c|}{ Monthly } \\
\hline & \multicolumn{6}{|c|}{ Average observations } \\
\hline & Coefficient & Std. Error & Prob. & Coefficient & Std. Error & Prob. \\
\hline$\beta_{0}$ (Constant) & 0.0629 & 0.0055 & 0.0000 & 0.0615 & 0.0075 & 0.0000 \\
\hline$\beta_{1}$ (Dummy) & -0.0041 & 0.0072 & 0.5723 & 0.0030 & 0.0104 & 0.7745 \\
\hline$\beta_{2}$ (Slope) & 0.4214 & 0.3873 & 0.2778 & 0.0377 & 0.1901 & 0.8436 \\
\hline$\beta_{3}$ (Slope*Dummy) & -0.9421 & 0.5189 & 0.0709 & -0.0577 & 0.2948 & 0.8455 \\
\hline Adjusted R-squared & & 0.0166 & & & -0.0629 & \\
\hline F-statistic & & 2.2387 & & & 0.0332 & \\
\hline Prob(F-statistic) & & 0.0847 & & & 0.9917 & \\
\hline
\end{tabular}




\section{FIGURES}

\section{Figure 1: Visual representation of the series.}

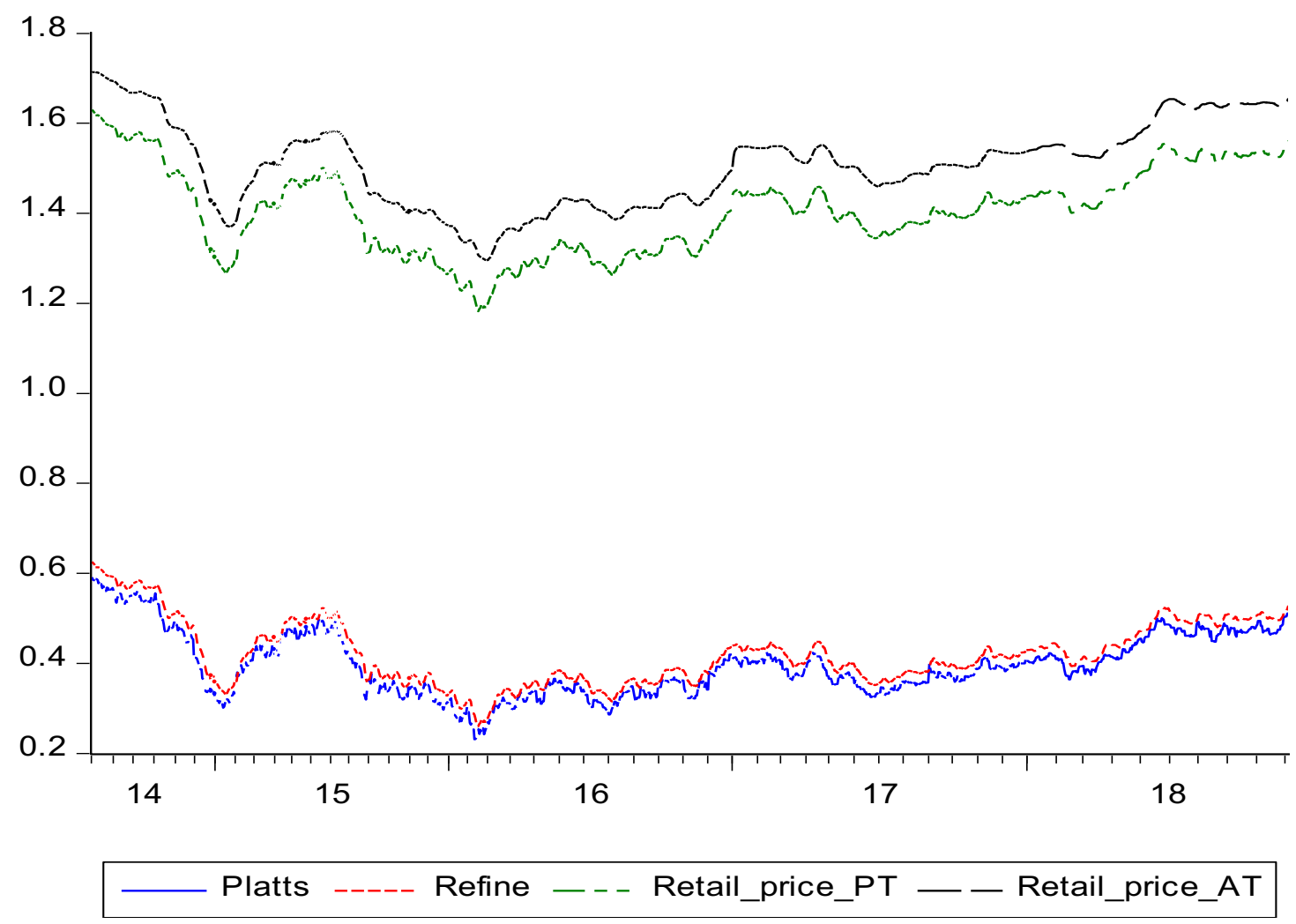

Note: Retail_price_PT refers to the pre-tax retail fuel prices, whereas Retail_price_AT denotes the after-tax retail fuel prices. 
Figure 2: The $\max _{K}\left(1-\frac{\sum_{t=1}^{T}\left(\widehat{u}_{t}^{2}\right)}{\sum_{t=1}^{T}\left(y_{t}^{(\text {ret_tax })}-\bar{y}^{(\text {ret_tax })}\right)^{2}}\right)$ for modelling the retailers' mark-up including the taxation effect.

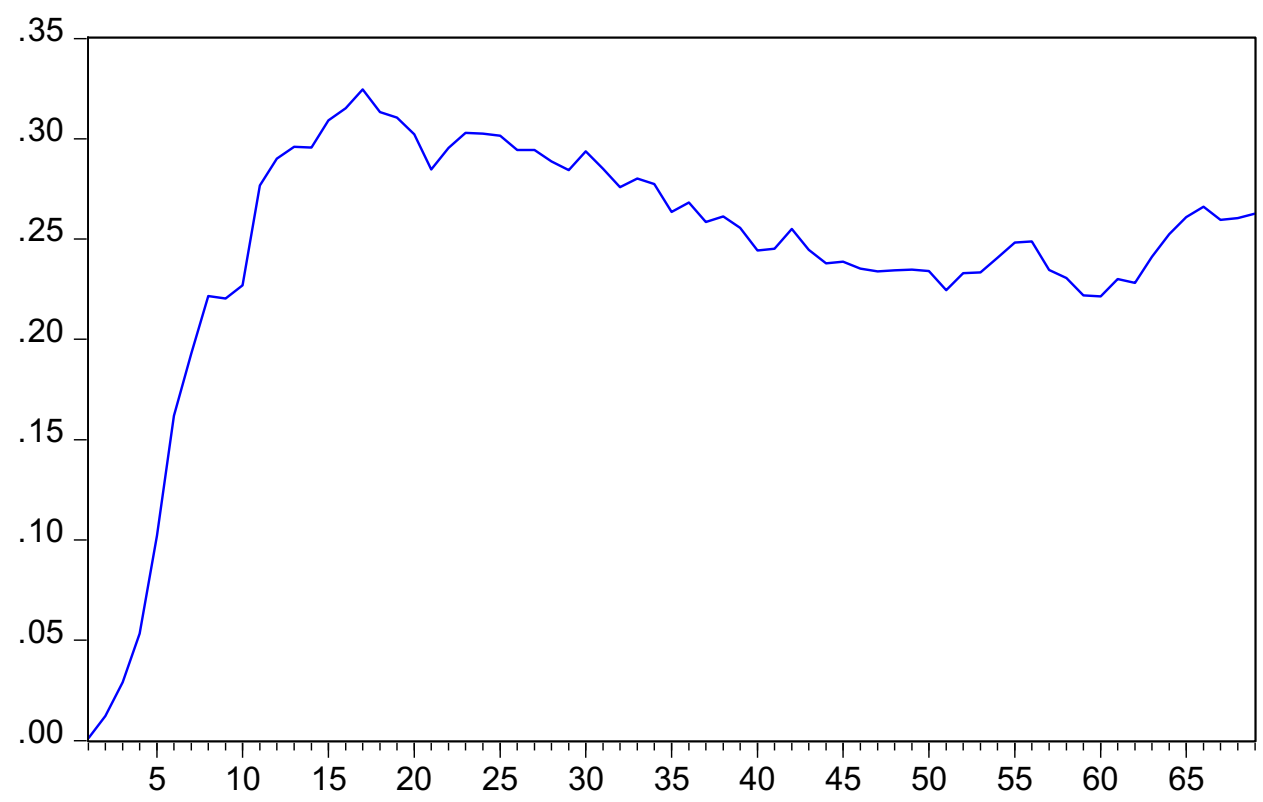

Note: The line shows the adjusted R-squared for the model in equation 1 (based on PLATTS prices) at each $K=1, . ., 70$ day. The $\mathrm{x}$-axis denotes the most recent days and the $\mathrm{y}$-axis refers to the adjusted R-squared. 
Figure 3: The $\max _{K}\left(1-\frac{\sum_{t=1}^{T}\left(\widehat{u}_{t}^{2}\right)}{\sum_{t=1}^{T}\left(y_{t}^{(\text {ret_tax })}-\bar{y}^{(\text {ret_tax })}\right)^{2}}\right)$ for modelling the retailers' mark-up including the taxation effect.

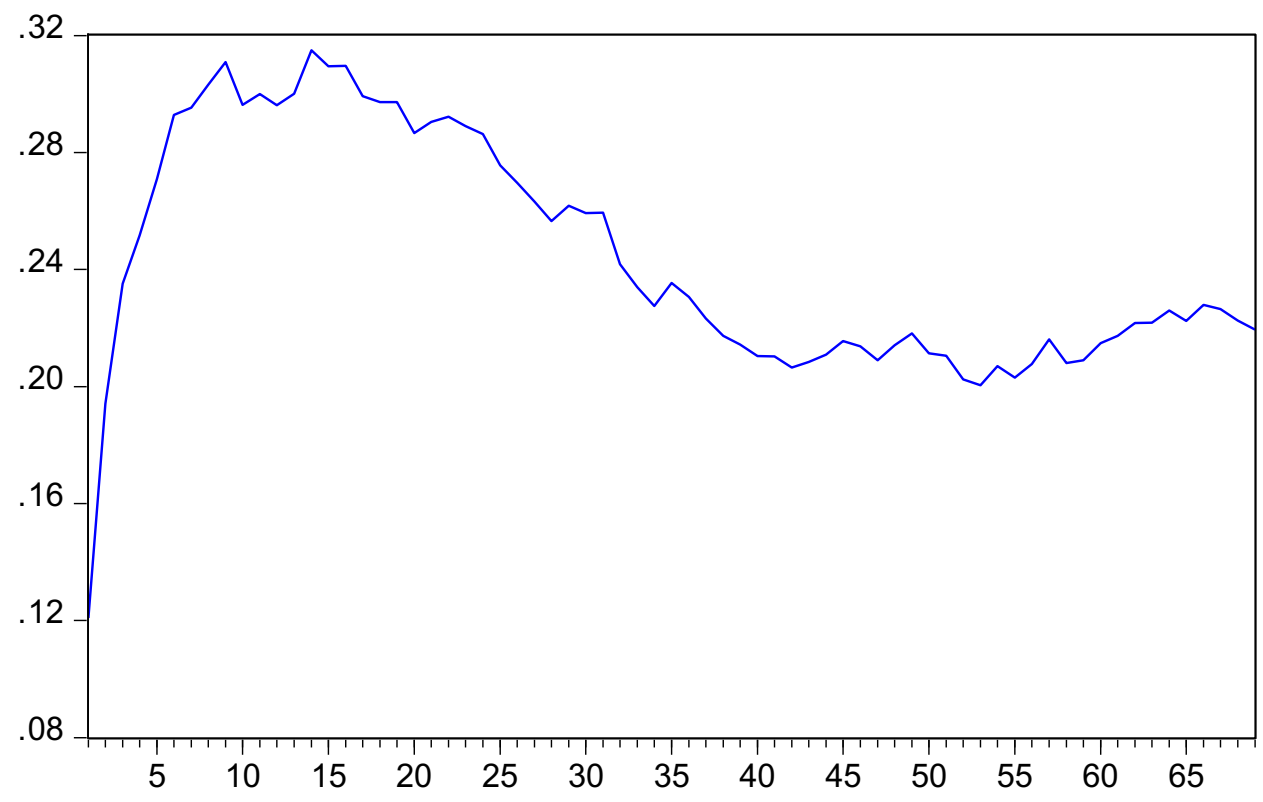

Note: The line shows the adjusted R-squared for the model in equation 1 (based on refined fuel prices) at each $K=1, . ., 70$ day. The x-axis denotes the most recent days and the $y$-axis refers to the adjusted R-squared. 
Figure 4: The $\max _{K}\left(1-\frac{\sum_{t=1}^{T}\left(\widehat{u}_{t}^{2}\right)}{\sum_{t=1}^{T}\left(y_{t}^{(r e f)}-\bar{y}^{(r e f)}\right)^{2}}\right)$ for modelling the refineries' mark-up.

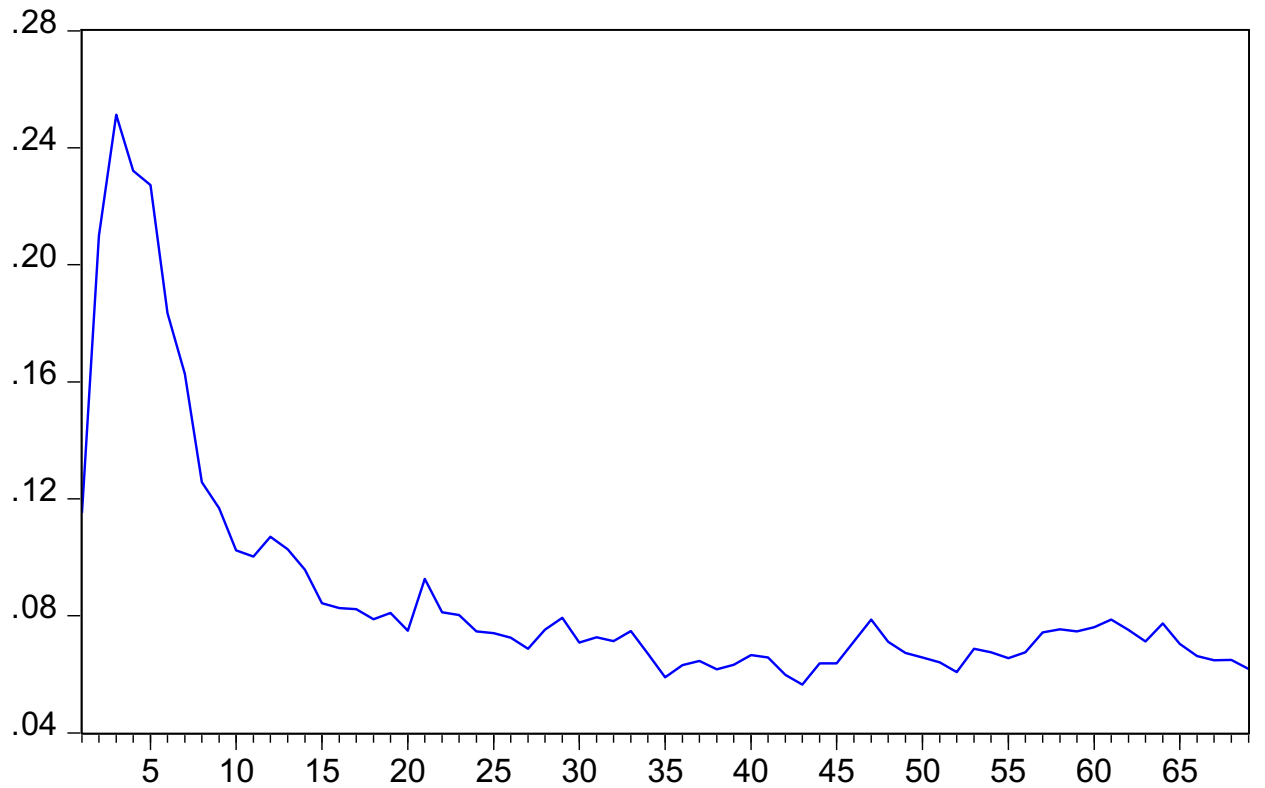

Note: The line shows the adjusted R-squared for the model in equation 9 at each $K=1, . ., 70$ day. The $\mathrm{x}$-axis denotes the most recent days and the y-axis refers to the adjusted R-squared. 
Figure 5: Scatterplot between the refineries' mark-up and the first difference in average $P L A T T S$ prices per litre.

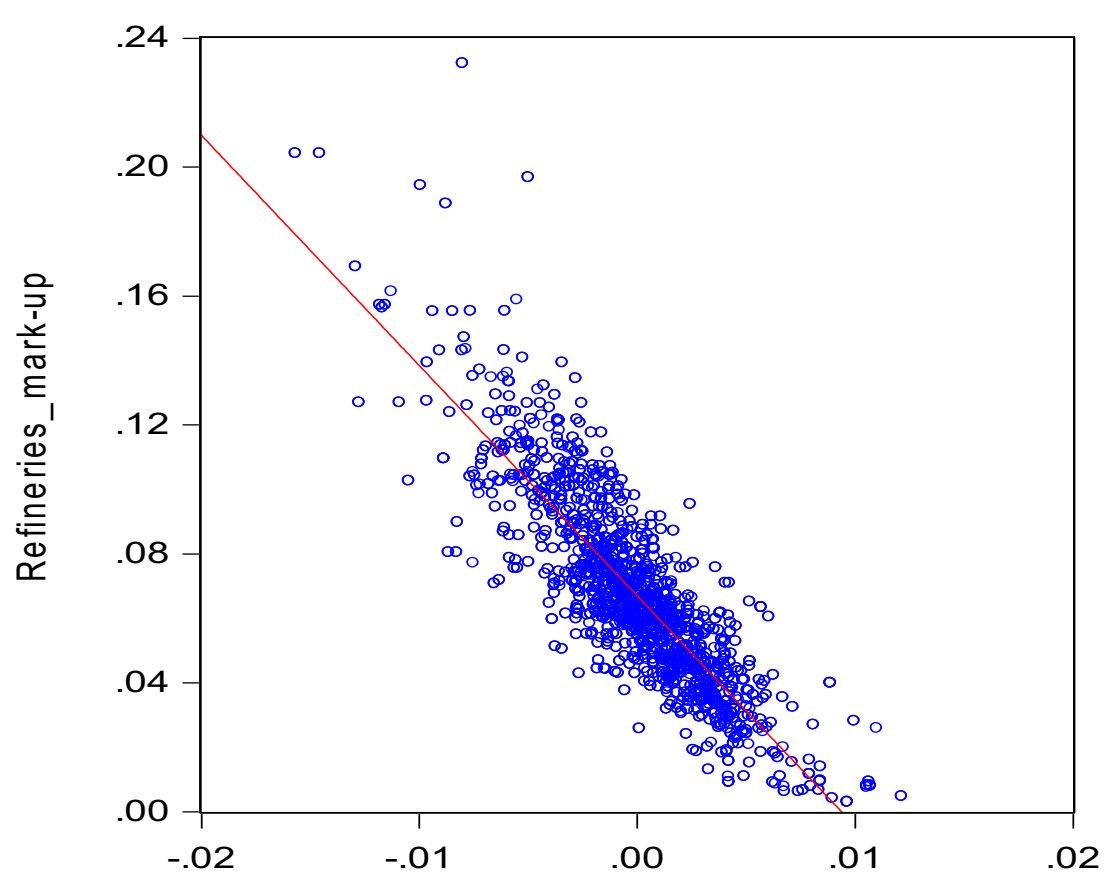

First difference in weekly average PLATTS prices 
Figure 6: Scatterplot between the refineries' mark-up and increasing/decreasing average $P L A T T S$ prices per litre. Increasing average $P L A T T S$ prices
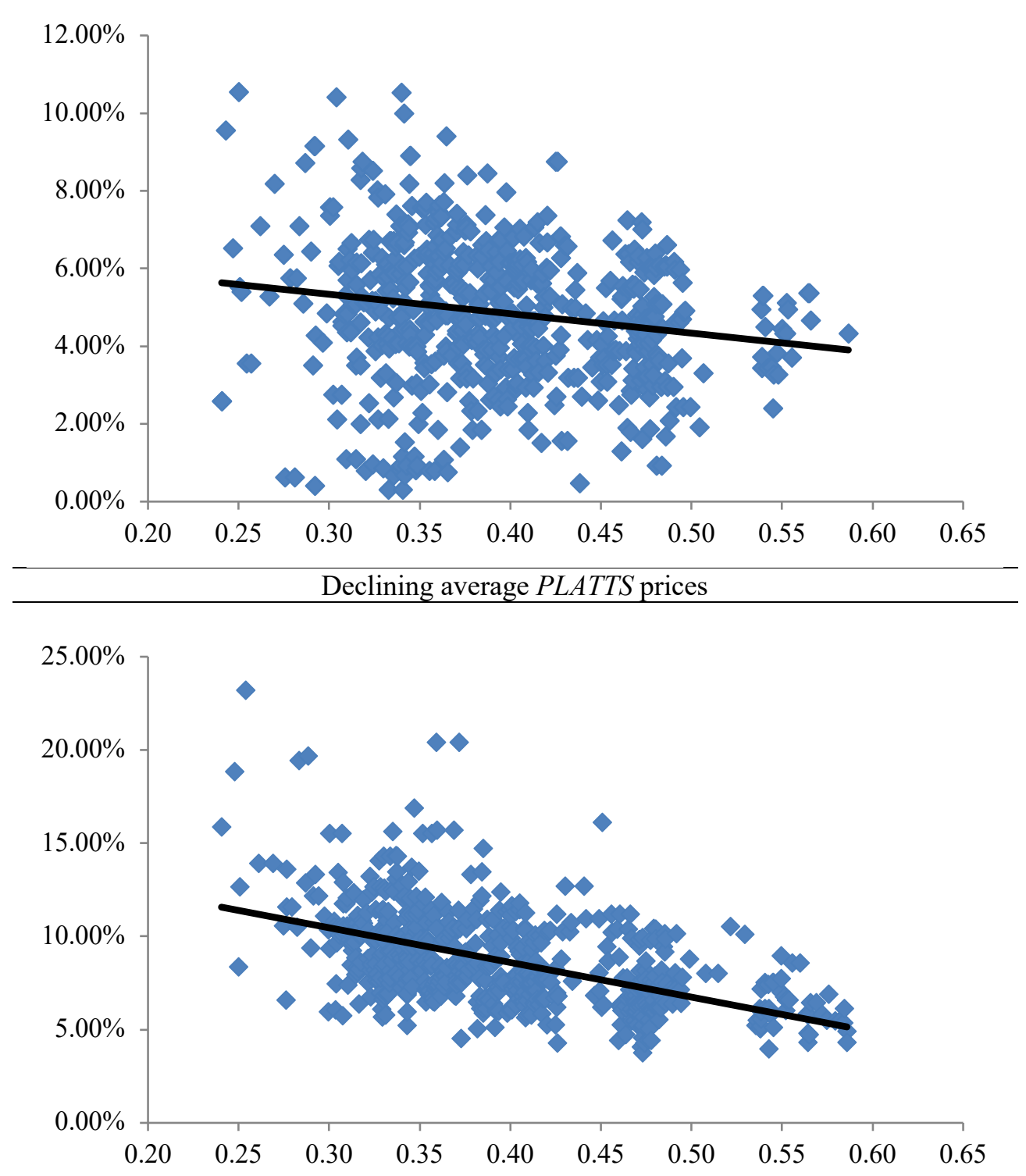

Note: The x-axes denote the 5-days moving average PLATTS prices per litre and the y-axes denote the refineries' mark-up. 
APPENDIX

Table A1: Retailers' mark-up (excluding taxes) based on PLATTS prices.

\begin{tabular}{lrrr}
\cline { 2 - 4 }$\gamma_{0}$ (Constant) & 0.0710 & 0.0002 & 0.0000 \\
$\gamma_{1}$ (Dummy) & 0.0057 & 0.0009 & 0.0000 \\
$\gamma_{2}$ (Slope) & -4.4692 & 0.2259 & 0.0000 \\
$\gamma_{3}$ (Slope*Dummy) & 1.8789 & 0.4338 & 0.0000 \\
Adjusted R-squared & & 0.4790 & \\
F-statistic & & 373 & \\
Prob(F-statistic) & & 0.0000 & \\
\hline
\end{tabular}
Std.

Note: HAC heteroscedasticity and autocorrelation robust standard errors are used.

Table A2: Retailers' mark-up (including taxes) based on PLATTS prices.

\begin{tabular}{lrrl}
\hline & & \multicolumn{1}{c}{ Std. } \\
& Coefficient & Error & Prob. \\
\cline { 2 - 4 }$\gamma_{0}$ (Constant) & 0.2394 & 0.0013 & 0.0000 \\
$\gamma_{1}$ (Dummy) & 0.0375 & 0.0060 & 0.0000 \\
$\gamma_{2}$ (Slope) & -15.986 & 1.3220 & 0.0000 \\
$\gamma_{3}$ (Slope*Dummy) & 9.0100 & 2.4875 & 0.0003 \\
Adjusted R-squared & & 0.2949 & \\
F-statistic & & 172 & \\
Prob(F-statistic) & & 0.0000 & \\
\hline
\end{tabular}

Note: HAC heteroscedasticity and autocorrelation robust standard errors are used.

\begin{tabular}{lrll}
\hline $\begin{array}{l}\text { Table A3: Retailers' mark-up } \\
\text { based on REFINED fuel prices. }\end{array}$ & (including & taxes) \\
\hline & \multicolumn{3}{c}{ Std. } \\
& Coefficient & Error & Prob. \\
\cline { 2 - 4 }$\gamma_{0}$ (Constant) & 0.0725 & 0.0007 & 0.0000 \\
$\gamma_{1}$ (Dummy) & 0.0035 & 0.0015 & 0.0199 \\
$\gamma_{2}$ (Slope) & -3.7674 & 0.4858 & 0.0000 \\
$\gamma_{3}$ (Slope*Dummy) & 0.8228 & 0.8471 & 0.3199 \\
Adjusted R-squared & & 0.4493 & \\
F-statistic & & 337 & \\
Prob(F-statistic) & & 0.0000 & \\
\hline
\end{tabular}

Note: HAC heteroscedasticity and autocorrelation robust standard errors are used. 
Table A4: Retailers' mark-up (excluding taxes) based on REFINED fuel prices.

$\delta_{0}$ (Constant)

\begin{tabular}{rll} 
Coefficient & Std. & \\
\hline 0.2436 & 0.0045 & 0.0000 \\
0.0219 & 0.0091 & 0.0161 \\
-13.191 & 3.1669 & 0.0000 \\
2.3252 & 4.8817 & 0.6339 \\
& 0.2782 & \\
& 159 & \\
& 0.0000 &
\end{tabular}

$\delta_{1}$ (Dummy)

0.0000

$\delta_{2}$ (Slope)

$\delta_{3}$ (Slope*Dummy)

Adjusted R-squared

F-statistic

Note: HAC heteroscedasticity and autocorrelation robust standard errors are used.

Table A5: Refineries' mark-up based on PLATTS prices.

$\beta_{0}$ (Constant)

$\beta_{1}$ (Dummy)

$\beta_{2}$ (Slope)

$\beta_{3}$ (Slope*Dummy)

Adjusted R-squared

F-statistic

Prob(F-statistic)

Note: HAC heteroscedasticity and autocorrelation robust standard errors are used. 
Figure A1: The heat map of $\max _{K, \omega}\left(1-\frac{\sum_{t=1}^{T}\left(\hat{u}_{t}^{2}\right)}{\sum_{t=1}^{T}\left(y_{t}^{(\text {ret_tax })}-\bar{y}^{(\text {ret_tax })}\right)^{2}}\right)$ for modelling the retailers' mark-up based on Platts prices.

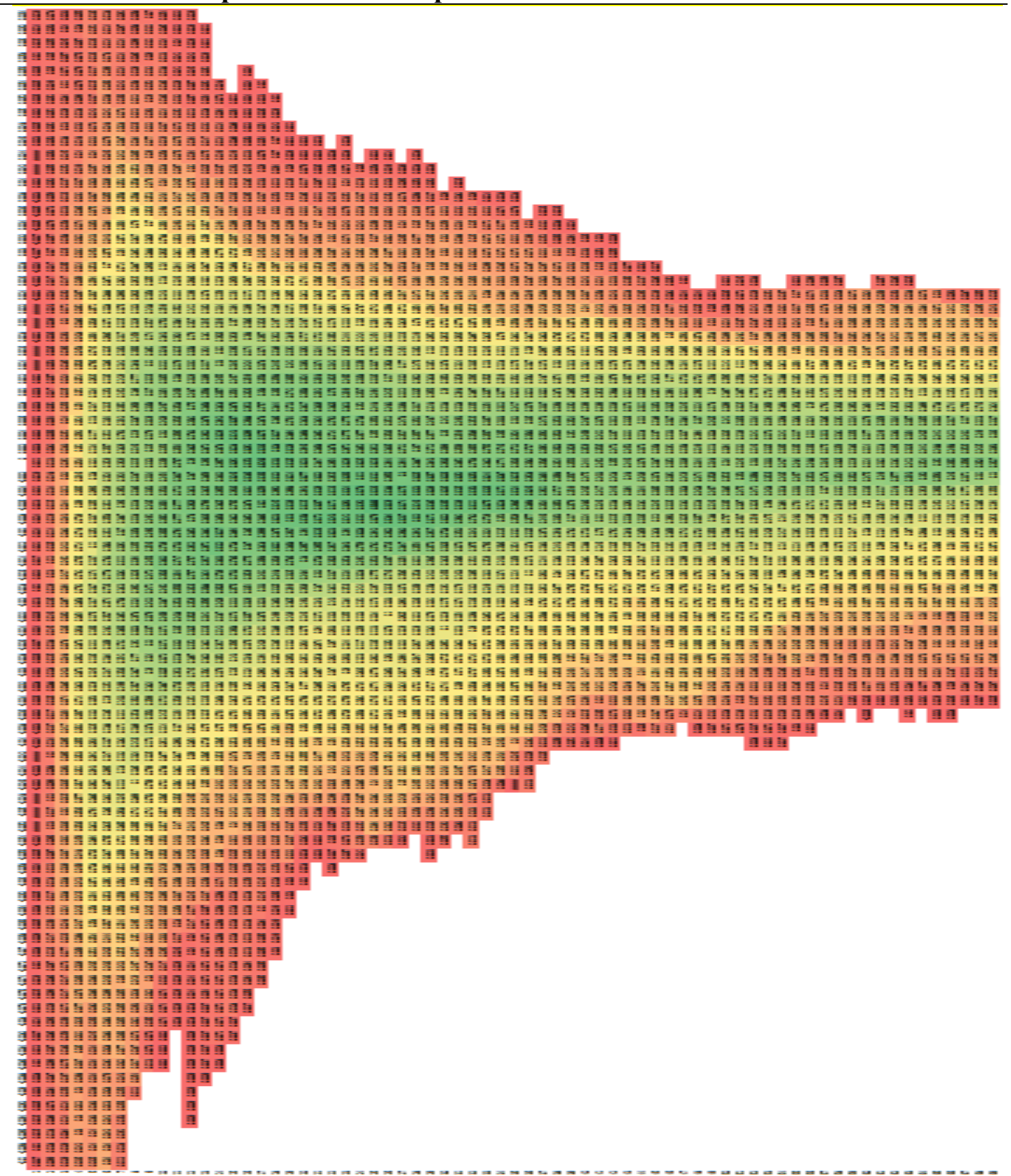

Note: The green(red) colour shows the highest(lowest) values of $\max _{K, \omega}($.$) . The \mathrm{x}$-axis refers to the values of $K$, for $K \ni[0,70]$ whereas the y-axis refers to the values of $\omega$, for $\omega \ni[-0.01,0.01]$. 
Figure A2: The heat $\operatorname{map}$ of $\max _{K, \omega}\left(1-\frac{\sum_{t=1}^{T}\left(\widehat{u}_{t}^{2}\right)}{\sum_{t=1}^{T}\left(y_{t}^{(\text {ret_tax })}-\bar{y}^{(\text {ret_tax })}\right)^{2}}\right)$ for modelling the retailers' mark-up based on refined fuel prices.

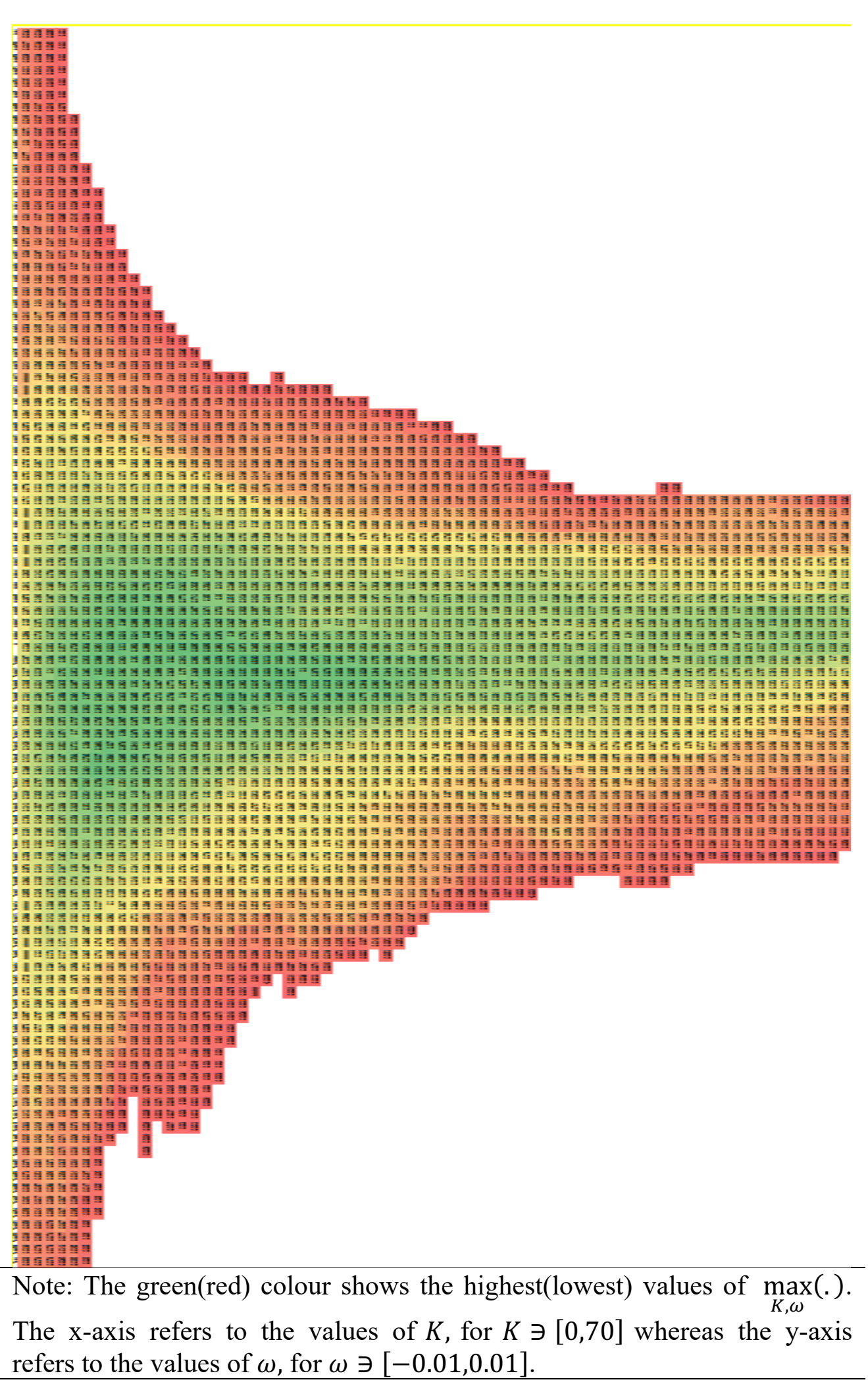


Figure A3: The $\max _{K, \omega}\left(1-\frac{\sum_{t=1}^{T}\left(\widehat{u}_{t}^{2}\right)}{\sum_{t=1}^{T}\left(y_{t}^{(r e f)}-\bar{y}^{(r e f)}\right)^{2}}\right)$ for modelling the refineries' mark-up based on platts prices.

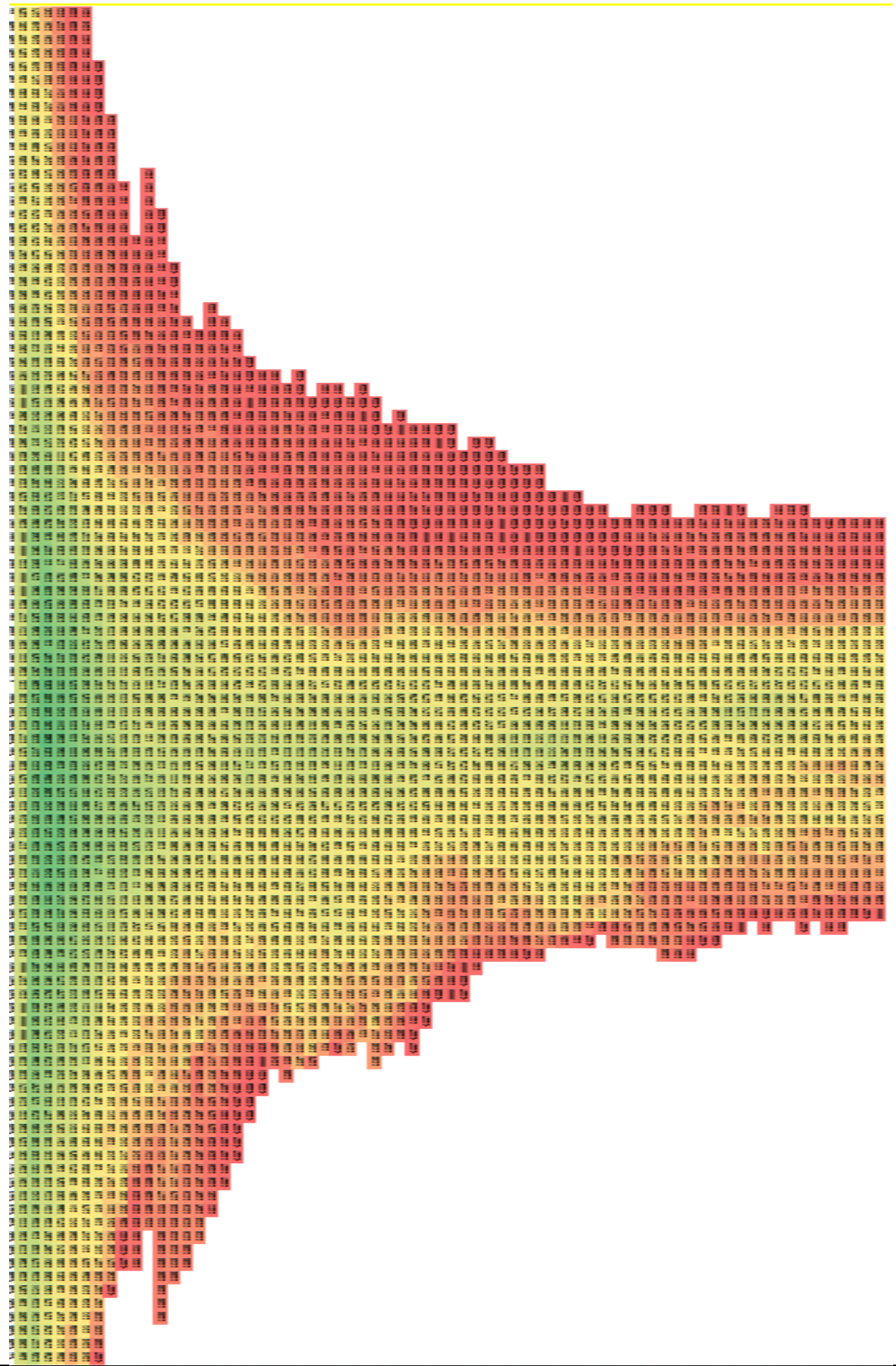

Note: The green(red) colour shows the highest(lowest) values of $\max _{K, \omega}($.$) .$ The $\mathrm{x}$-axis refers to the values of $K$, for $K \ni[0,70]$ whereas the $\mathrm{y}$-axis refers to the values of $\omega$, for $\omega \ni[-0.01,0.01]$. 